\title{
Immunosuppressive Medication and Non-Rejection-Related Complications Following Heart Transplantation
}

\author{
Dumitru Costel', Dana Ghiga², Septimiu Voidazan³, Alexandra Grosan, Dan Simpalean5, Anca Sin 6 \\ 1 "George Emil Palade" University of Medicine, Pharmacy, Science and Technology, Târgu Mureș, Romania \\ 2 Discipline of Methodology of Medical Scientific Research, "George Emil Palade” University of Medicine, Pharmacy, Science and \\ Technology, Târgu Mureș, Romania \\ 3 Discipline of Epidemiology, "George Emil Palade" University of Medicine, Pharmacy, Science and Technology, Târgu Mureș, Romania \\ 4 Discipline of Pharmacology and Clinical Pharmacy, "George Emil Palade" University of Medicine, Pharmacy, Science and \\ Technology, Târgu Mureș, Romania \\ 5 "Filantropia” Clinical Hospital, Bucharest, Romania \\ 6 Discipline of Cell Biology, "George Emil Palade" University of Medicine, Pharmacy, Science and Technology, Târgu Mureș, Romania
}

\section{CORRESPONDENCE}

\section{Dumitru Costel}

Str. Gheorghe Marinescu nr. 38

540139 Târgu Mureș, Romania

Tel: +40 265215551

E-mail: costimv@yahoo.com

\section{ARTICLE HISTORY}

Received: April 30, 2020

Accepted: June 16, 2020
Dana Ghiga • Str. Gheorghe Marinescu nr. 38, 540139 Târgu Mureș, Romania. Tel: +40 265215551 Simona Voidazan - Str. Gheorghe Marinescu nr. 38 , 540139 Târgu Mureș, Romania. Tel: +40 265215551 Alexandra Grosan • Str. Gheorghe Marinescu nr. 38 , 540139 Târgu Mureș, Romania. Tel: +40 265215551 Dan Simpalean • Blv. Ion Mihalache nr. 11, 011171 București, Romania. Tel: +40 213188937

Anca Sin • Str. Gheorghe Marinescu nr. 38, 540139 Târgu Mureș, Romania. Tel: +40 265215551

\begin{abstract}
Background: Although the clinical evolution of a patient with heart failure is initially improved by transplantation, a number of potential complications may occur in the post-transplant period, which may be directly related to the effects of chronic immunosuppression. The purpose of this study was to analyze the occurrence and frequency of post-transplant complications related to immunosuppressive treatment in the Institute of Cardiovascular Diseases and Transplantation of Târgu Mureș, Romania. Material and methods: This is a descriptive study including 53 patients out of a total of 71 patients who underwent cardiac transplantation between 2000 and 2017 in the Institute of Cardiovascular Disease and Cardiac Transplantation in Târgu Mureș, Romania. Data were collected from the patient files and included demographic, clinical and laboratory data, as well as information about post-transplant complications related to immunosuppressive treatment. Results: The mean age of patients undergoing heart transplantation was $40.72 \pm 14.07$ years, the majority of patients being male $(84.91 \%)$ and living in an urban environment (56.60\%). The average length of hospital stay was 33.6 days. From the total number of patients, 7 (13.2\%) presented post-transplantation bacterial infections, while antibodies indicating the presence or history of B hepatitis, toxoplasma, and cytomegalovirus infection were identified with a relatively high incidence in the study population. Conclusions: Infections following surgery are probably the most common post-transplant pathology, the primary reason being the administration of immunosuppressive medication.
\end{abstract}

Keywords: cardiac transplant, postoperative complications, immunosuppression 


\section{INTRODUCTION}

Heart transplantation is the treatment of choice in severe cases of end-stage heart failure. ${ }^{1,2}$ In the absence of heart transplantation, the management of these critical cases is associated with a poor prognosis. ${ }^{3-5}$ Cardiac transplantation has shown a very good long-term survival rate in patients with dilative cardiomyopathy and end-stage coronary heart disease, with up to $85 \%$ survival in the first year after transplant, $75 \%$ at 5 years, and $56 \%$ at 10 years. ${ }^{6,7} \mathrm{Al}-$ though the clinical evolution of a patient with heart failure is initially improved by transplantation, a number of potential complications may occur following the intervention, which may be directly related to the effects of chronic immunosuppression, mandatory to prevent the rejection of transplanted hearts.

\section{AIM OF THE STUDY}

The purpose of this study was to analyze the occurrence and frequency of post-transplant complications related to immunosuppressive treatment in the Institute of Cardiovascular Diseases and Transplantation of Târgu Mureș, Romania.

\section{MATERIAL AND METHODS}

This is a descriptive study including 53 patients out of a total of 71 patients who underwent cardiac transplantation between 2000 and 2017 in the Institute of Cardiovascular Diseases and Cardiac Transplantation in Târgu Mureș,
Romania. Data were collected from the patient files and included demographic, clinical and laboratory data, as well as information about post-transplant complications related to immunosuppressive treatment. The collected data were analyzed using descriptive statistical methods. Continuous variables were expressed as mean \pm standard deviation, and quantitative data as proportions. The study was conducted in accordance with the ethical principles stated in the Declaration of Helsinki, and in agreement with the good clinical practice measures. The study was approved by the local ethics committee, and all patients gave informed consent for participation in the study.

\section{RESULTS}

The mean age of patients undergoing heart transplantation was $40.72 \pm 14.07$ years, the majority of patients being male (84.91\%) and living in an urban environment (56.60\%). The average length of hospital stay was 33.6 days.

\section{Infectious complications}

From the total number of patients, 7 (13.2\%) presented post-transplantation bacterial infections: Klebsiella pneumoniae was found in 2 cases, while Clostridium difficile, Staphylococcus aureus, methicillin-sensitive Staphylococcus aureus (MSSA), Staphylococcus epidermidis, and Pseudomonas aeruginosa were identified in the rest of 5 cases.

Viral infections were also diagnosed with a high frequency following heart transplantation. Antibodies indicating the presence or history of B hepatitis, Toxoplasma, and $C y$ -

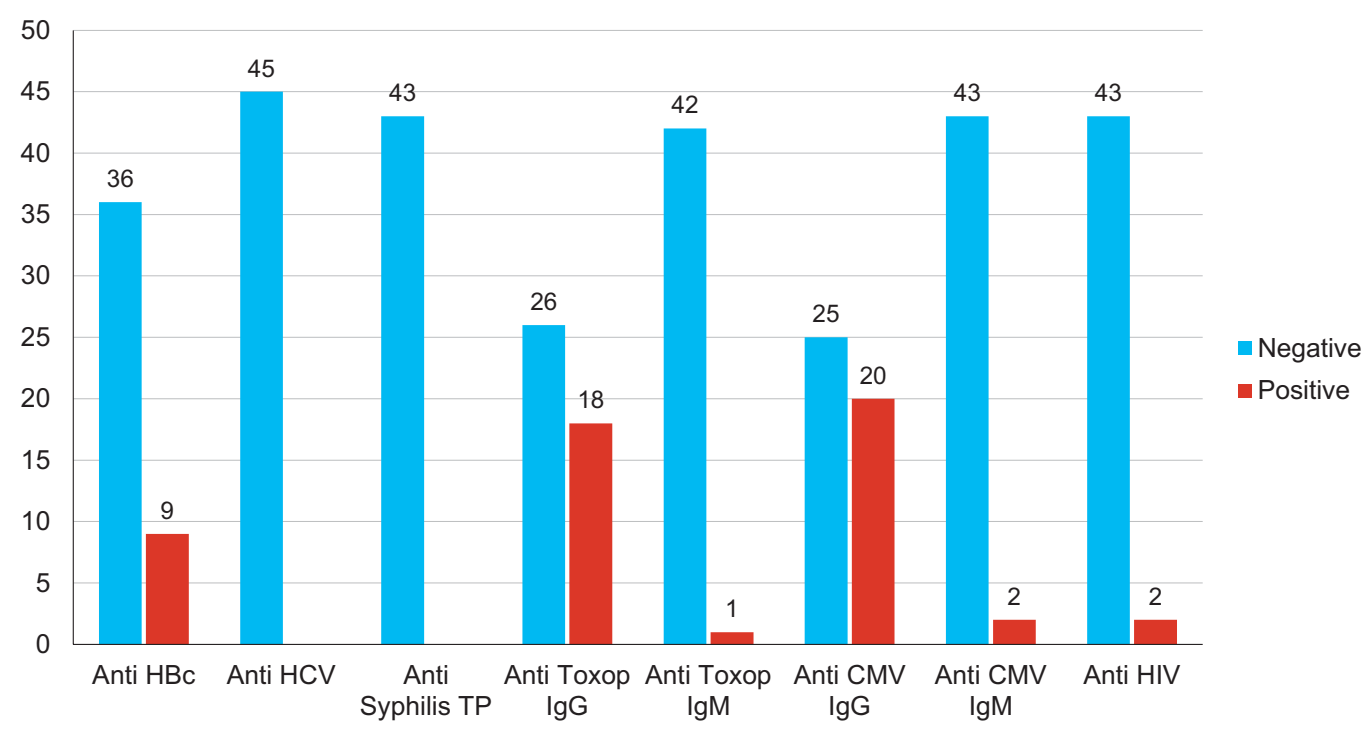

FIGURE 1. The distribution of positive-tested antibodies in the studied population 
tomegalovirus (CMV) infection were identified with a relatively high incidence in the study population (Figure 1).

\section{Renal dysfunction}

Cyclosporine-induced nephrotoxicity remains a medical challenge in cardiac post-transplant management. In our study, only 1 (2\%) patient out of 53 was diagnosed with renal failure post-cardiac transplant. Following heart transplantation, the mean serum levels of urea and creatinine were $61.13 \pm 30.87 \mathrm{mg} / \mathrm{dL}$ and $1.002 \pm 0.932 \mathrm{mg} / \mathrm{dL}$, respectively.

\section{Hyperlipidemia}

We assessed the incidence of hyperlipidemia with multifactorial origin and found mean cholesterol values of 381.0 $\pm 175.0 \mathrm{mg} / \mathrm{dL}$ and mean LDL-cholesterol values posttransplant of $220.1 \pm 63.38 \mathrm{mg} / \mathrm{dL}$.

\section{DISCUSSIONS}

\section{Post-transplant pathology - development of new clinical conditions favoring infections}

According to published literature, post-transplant evolution is frequently marked by the development of new clinical conditions which, associated with immunosuppressive treatment, may favor the development of severe infections, reducing the defensive capacity of the body. These conditions include new-onset diabetes, hypertension, hyperlipidemia, renal dysfunction, tumors, or thyroid diseases.

Almost $20 \%$ of patients surviving transplant develop diabetes in the first year after the intervention, but 5 years later only $15 \%$ can be classified as diabetic. This is most likely caused by the use of decreasing doses of corticosteroids. It has not yet been proven whether transplant patients need to be managed differently in terms of blood glucose, glycated hemoglobin, or medicinal agents used in therapy. ${ }^{8,9}$ Data from the international literature also show that hypertension after transplantation is common, with an incidence of $70-90 \%$ in patients treated with cyclosporine and $30-50 \%$ in those treated with tacrolimus. ${ }^{10,11}$ Both tacrolimus and cyclosporine may influence blood pressure levels and favor hyperlipidemia, as shown by Han et al. ${ }^{12}$

Regarding renal dysfunction, it has been demonstrated that immunosuppressive therapy with cyclosporine has improved graft function and survival time in transplant patients. However, cyclosporine-induced nephrotoxicity remains a medical challenge for post-heart transplant management. Cyclosporine, a highly nephrotoxic immunosuppressive agent, causes an initially reversible decrease in glomerular filtration rate (GFR), possibly through arteriolar vasoconstriction. The mechanisms by which renal vasoconstriction and decreased filtration rates occur are not known, but it has been suggested that abnormalities of endogenous vasoconstrictor and vasodilator mechanisms may be responsible. In this context, an oral dose of cyclosporine $(5 \mathrm{mg} / \mathrm{kg})$ was found to strongly affect renal hemodynamics, both in patients with cardiac transplantation and chronic treatment and in healthy volunteers, in whom $10 \mathrm{mg} / \mathrm{kg}$ cyclosporine caused an $18 \%$ decrease in GFR. Increased serum creatinine levels due to cyclosporine may be associated with hypertension, a disproportionate increase in serum urea, hyperkaliemia, increased uric acid levels, mild proteinuria (usually less than $1 \mathrm{~g} / 24 \mathrm{~h}$ ), and decreased fractional sodium excretion. Increased blood pressure may be associated with decreased sodium excretion, stimulation of the renin-angiotensin system, increased local endothelin synthesis and/or decreased local nitric oxide synthesis. Treatment interruption or lowering the dose of cyclosporine may sometimes stabilize kidney function, but even when renal function remains stable, the morphological lesions and proteinuria may progress further. ${ }^{13-15}$ Tacrolimus, another immunosuppressive agent, is also associated with a higher risk of nephrotoxicity. This reaction may be explained by the increase in the production of oxygen free radicals that induce kidney damage. ${ }^{13-15}$

Hyperlipidemia is one of the most common metabolic dysfunctions encountered in transplanted patients, with an incidence of $60-80 \%$. Studies show that tacrolimus and cyclosporine can influence blood pressure (hypertension) and hyperlipidemia. ${ }^{16-18}$ It has a multifactorial origin, with mechanisms dependent on abnormalities of the pre-existing lipid status, cyclosporine therapy, and corticosteroids. Discontinuation of corticosteroid treatment has been shown to be associated with low cholesterol. Cyclosporine A (CsA)-induced hyperlipidemia is already known and is a clinically significant problem. CsA affects the metabolism of lipids and lipoproteins; however, the basic mechanisms that cause dyslipidemia are not well known. Additional studies are needed to help identify immunosuppressive agents that do not cause hyperlipidemia, or to support the development of strategies to effectively monitor CsAinduced hyperlipidemia. ${ }^{19}$

Youn et al. performed a retrospective analysis on 17,587 patients from the International Society of Heart and Lung Transplant (ISHLT) registry over a 10-year period (20012011 ) in order to identify the occurrence of malignant tumors after heart transplantation. ${ }^{20}$ Over $10 \%$ of the moni- 
tored patients have developed de novo malignancy in 1 to 5 years after transplantation. The authors reported a $12.4 \%$ increase in de novo malignancies in patients transplanted between 2006 and 2011, compared with 10\% in patients treated between 2000 and 2006, resulting in an absolute increase of $2.4 \%$. Skin cancer accounted for most of this increase, solid organ malignancy was responsible for a small increase, and the incidence of post-transplant lymphoproliferative disease (PTLD) was low (approximately 1\%) in both cohorts compared to the previously reported $3 \%$ to $9 \% .{ }^{21}$ These results are diametrically opposed to those in pediatric heart transplant patients, in whom PTLD is the major post-transplant malignancy. This low incidence may also show that PTLD related to Epstein-Barr virus infection occurs relatively early, usually in the first year after transplantation, and in this analysis, these patients were not included. Although it has been observed that the change in immunosuppression has led to a decrease in the incidence of PTLD, the prevention and more effective treatment of infectious diseases and/or under-reporting to the ISHLT registry remains unclear. ${ }^{22}$

Thyroid diseases can also deteriorate in most heart transplant patients. After cardiac transplant, the serum levels of TSH hormone should be monitored and controlled in all patients, especially in those with a history of thyroid disease. ${ }^{23}$

\section{Post-transplant pathology - infections related to immunosuppressive treatment}

In transplant patients, selective inhibitors of cytokine production and function (tacrolimus, cyclosporine), immunosuppressive antimetabolites (mycophenolate mofetil), and antivirals (valganciclovir) are frequently used to prevent graft rejection.

Infections following surgery are probably the most common post-transplant pathology, the primary reason for this being the use of immunosuppressive medication. The latter depends on each patient's predilection for rejection, which has been shown to decrease exponentially over time. ${ }^{24}$ Bacteria and viruses are responsible for more than $80 \%$ of post-transplant infections. ${ }^{25,26}$ The most common bacterial infections after cardiac transplantation are nosocomial ones, caused by intravascular catheters, infected gas lines, or occult pneumonias caused by Gram-negative germs. ${ }^{27}$

In our study, microbiological tests were performed in all 53 patients, starting with the 3rd postoperative day. Twelve per cent of patients developed bacterial infections from the 7 th to the 9 th postoperative day, manifested by fever and elevated acute phase inflammatory reactants and confirmed by microbiology.

The most common viral infections following cardiac surgery are generally caused by herpes viruses (CMV, herpes zoster, and herpes simplex). ${ }^{28}$ Infections with CMV represent major causes of morbidity, being associated with a high rate of readmission after heart transplantation. In a recent study, data on cytomegalovirus infection were analyzed in 1,553 patients undergoing heart transplantation from 26 centers in the Cardiac Transplant Research Database Group, the results indicating 230 confirmed cytomegalovirus infections, of which 16 were proven fatal (6\%).28 In the same study, $12 \%$ of the 200 patients with CMV infection had a recurrent infection during a mean follow-up of 13.9 months..$^{28}$ In our study, $44.44 \%$ of patients have developed a CMV infection, while $40.91 \%$ of them tested positive for Toxoplasma IgG antibodies.

\section{CONCLUSIONS}

Infections following surgery are probably the most common post-transplant pathology, the primary reason for this phenomenon being immunosuppressive medication. The administration of immunosuppressive agents is dependent on the patient's predilection for the rejection reaction, which decreases exponentially over time. Our experience has shown that bacteria and viruses are responsible for over $80 \%$ of post-transplant infections. The evaluation of post-transplant cardiac complications should be a priority, as they hold a negative impact on the post-operative evolution of heart transplant patients.

\section{CONFLICT OF INTEREST}

Nothing to declare.

\section{REFERENCES}

1. Hosenpud JD, Bennett LE, Keck BM, Boucek MM, Novick RJ. The Registry of the International Society for Heart and Lung Transplantation: eighteenth Official Report-2001. J Heart Lung Transplant. 2001;20:805-815

2. Mangini S, Alves BR, Silvestre $\mathrm{OM}$, et al. Heart transplantation: review. Einstein (Sao Paulo). 2015;13:310-318.

3. Custódio IL, Lima FE, Lopes MV, et al. Results of medium-term survival in patients undergoing cardiac transplantation: institutional experience. Rev Bras Cir Cardiovasc. 2013;28:470-476.

4. Fiorelli Al, Coelho GHB, Oliveira Junior JL, Oliveira AS. Heart failure and heart transplantation. Rev Med. 2008; 87:105-120.

5. Aranda JM Jr, Hill J. Cardiac transplant vasculopathy. Chest. 2000;118:17921800 .

6. Wilhelm MJ. Long-term outcome following heart transplantation: current perspective. J Thorac Dis. 2015;7:549-551.

7. Lund LH, Edwards LB, Kucheryavaya AY, et al. The registry of the International Society for Heart and Lung Transplantation: thirty-first official adult heart transplant report - 2014; focus theme: retransplantation. J Heart Lung Transplant. 2014;33:996-1008. 
8. Marchetti P. New-onset diabetes after transplantation. J Heart Lung Transplant. 2004;23(5 Suppl):S194-S201

9. Moro JA, Martínez-Dolz L, Almenar L, et al. Impacto de la diabetes mellitus en el paciente con trasplante cardiaco [Impact of diabetes mellitus on heart transplant recipients]. Rev Esp Cardiol. 2006:59:1033-1037.

10. Patel J, Kittleson M, Czer L, et al. Severity of Hypertension After Heart Transplant: Does It Impact Outcome? J Heart Lung Transplant. 2016;35:S295.

11. Aparicio LS, Alfie J, Barochiner J, et al. Hypertension: the neglected complication of transplantation. International Scholarly Research Notices. 2013:165937.

12. Han SY, Mun KC, Choi HJ, et al. Effects of cyclosporine and tacrolimus on the oxidative stress in cultured mesangial cells. Transplant Proc. 2006;38:2240-2241.

13. Herlitz $H$, Lindelöw B. Renal failure following cardiac transplantation Nephrol Dial Transplant. 2000;15:311-314.

14. Straathof K, Anoop P, Allwood Z, et al. Long-term outcome following cyclosporine-related neurotoxicity in paediatric allogeneic haematopoietic stem cell transplantation. Bone Marrow Transplant. 2017;52:159-162.

15. van Hooff JP, Christiaans MH, van Duijnhoven EM. Evaluating mechanisms of post-transplant diabetes mellitus. Nephrol Dial Transplant. 2004;19:vi8vi12.

16. Øzbay A. Diabetogenicity of Cyclosporine and Tacrolimus (Doctoral dissertation). Faculty of Health Sciences, Aarhus University; 2011.

17. Kockx M, Kritharides L. Cyclosporin A-induced hyperlipidemia. In: Lipoproteins-Role in Health and Diseases. Rijeka: InTech Publishers, 2012; p. 337-354.

18. Youn JC, Stehlik J, Wilk AR, et al. Temporal Trends of De Novo Malignancy Development After Heart Transplantation. J Am Coll Cardiol. 2018;71:4049
19. Kumarasinghe $G$, Lavee $O$, Parker $A$, et al. Post transplant lymphoproliferative disease in heart and lung transplantation: defining risk and prognostic factors. J Heart Lung Transplant. 2015;34:1406-1414.

20. Mancini D, Rakita V. Malignancy Post Heart Transplantation. J Am Coll Cardiol. 2018;71:50-52

21. Simonenko M, Fedotov $P$, Sazonova $Y$, et al. Thyroid Disorders in Recipients After Heart Transplantation. Transplantation. 2018;102:826.

22. Jha V. Post-transplant infections: An ounce of prevention. Indian $J$ Nephrol. 2010;20:171-178.

23. Montoya JG, Giraldo LF, Efron B, et al. Infectious complications among 620 consecutive heart transplant patients at Stanford University Medical Center. Clin Infect Dis. 2001;33:629-640.

24. Rostad CA, Wehrheim K, Kirklin JK, et al. Bacterial infections after pediatric heart transplantation: Epidemiology, risk factors and outcomes. J Heart Lung Transplant. 2017:36:996-1003.

25. Guggenbichler JP, Assadian O, Boeswald M, Kramer A. Incidence and clinical implication of nosocomial infections associated with implantable biomaterials - catheters, ventilator-associated pneumonia, urinary tract infections. GMS Krankenhhyg Interdiszip. 2011;6:Doc18.

26. Echenique IA, Angarone MP, Rich JD, Anderson AS, Stosor V. Cytomegalovirus infection in heart transplantation: A single center experience. Transpl Infect Dis. 2018;20:e12896

27. Carratalà J, Montejo M, Pérez-Romero P. Infections caused by herpes viruses other than cytomegalovirus in solid organ transplant recipients. Enferm Infecc Microbiol Clin. 2012;30:63-69.

28. Kirklin JK, Naftel DC, Levine TB, et al. Cytomegalovirus After Heart Transplantation. Risk Factors for Infection and Death: A Multiinstitutiona Study. The Cardiac Transplant Research Database Group. J Heart Lung Transplant. 1994;13:394-404. 